\title{
A Functional Respiratory Imaging Approach to the Effect of an Oscillating Positive Expiratory Pressure Device in Chronic Obstructive Pulmonary Disease
}

This article was published in the following Dove Press journal: International Journal of Chronic Obstructive Pulmonary Disease

\author{
Glenn Leemans (iD) ${ }^{1,2}$ \\ Dennis Belmans ${ }^{2}$ \\ Cedric Van Holsbeke (iD ${ }^{2}$ \\ Vladimir Kushnarev ${ }^{3}$ \\ Jason Sugget ${ }^{3}$ \\ Kris Ides \\ Dirk Vissers (D) \\ Wilfried De Backer iD ${ }^{4}$ \\ 'Department of Rehabilitation Sciences \\ and Physiotherapy, Faculty of Medicine \\ and Health Sciences, University of \\ Antwerp, Antwerp, Wilrijk, Belgium; \\ ${ }^{2}$ FLUIDDA nv, Antwerp, Kontich, \\ Belgium; ${ }^{3}$ Trudell Medical International, \\ London, Ontario, Canada; ${ }^{4}$ Faculty of \\ Medicine and Health Sciences, University \\ of Antwerp, Antwerp, Wilrijk, Belgium
}

Purpose: Chronic obstructive pulmonary disease (COPD) patients are prone to suffer from chronic bronchitis, which ultimately affects their quality of life and overall prognosis. Oscillating positive expiratory pressure (oPEP) devices are designed to aid in the mucus clearance by generating positive pressure pulses in the airways. The main aim of this study was to analyze the impact of a specific oPEP device - Aerobika ${ }^{\circledR}$ - on top of standard of care medication in COPD patients' lung dynamics and drug deposition.

Patients and Methods: In this single-arm pilot study, patients were assessed using standard spirometry tests and functional respiratory imaging (FRI) before and after a period of $15 \pm 3$ days of using the oPEP device twice daily (before their standard medication).

Results: The utilization of the oPEP device led to a significant increase of $2.88 \%$ in specific airway volume after two weeks (1.44 (SE: 0.18) vs 1.48 (SE: 0.19); 95\% CI = $[0.03 \%, 5.81 \%] ; \mathrm{p}=0.048)$. Moreover, the internal airflow distribution (IAD) was affected by the treatment: patients' changes ranged from $-6.74 \%$ to $4.51 \%$. Furthermore, IAD changes at the lower lobes were also directly correlated with variations in forced expiratory volume in one second and peak expiratory flow; conversely, IAD changes at the upper lobes were inversely correlated with these clinical parameters. Interestingly, this change in IAD was significantly correlated with changes in lobar drug deposition $\left(r^{2}=0.30, \mathrm{p}<0.001\right)$.

Conclusion: Our results support that the Aerobika device utilization leads to an improved airflow, which in turn causes a shift in IAD and impacts the drug deposition patterns of the concomitant medication in patients with COPD.

Keywords: mucus hypersecretion, airway clearance techniques, functional respiratory imaging, internal airflow distribution, drug deposition

\section{Plain Language Summary}

Patients with chronic obstructive pulmonary disease (COPD) often suffer from chronic bronchitis, which is characterized by an accumulation of mucus in their airways. This excessive mucus not only interferes in patients' daily life activities, but may also promote the development of disease complications and exacerbations. Aerobika ${ }^{\circledR}$ is a hand-held device designed to aid in the mucus clearance by generating positive pressure pulses in the airways. This study involved $10 \mathrm{COPD}$ patients and aimed to test whether the association of the Aerobika device to standard medication could improve patients' respiratory capacity.
Correspondence: Glenn Leemans Faculty of Medicine and Health SciencesUniversity of Antwerp, Universiteitsplein I, 2610 Wilrijk,

Antwerp, Belgium

Tel +32495348459

Email glenn.leemans@uantwerpen.be
International Journal of Chronic Obstructive Pulmonary Disease 2020:15 |26|-|268

| 26 |

DovePress f $y$ in

http://doi.org/10.2147/COPD.S242191 (c) (1) \&) $\odot 2020$ Leemans et al. This work is published and licensed by Dove Medical Press Limited. The full terms of this license are available at https://www.dovepress.com/terms (2) php and incorporate the Creative Commons Attribution - Non Commercial (unported, v3.0) License (http://creativecommons.org/licenses bly-n-c/3.0). By accessing the work you hereby accept the Terms. Non-commercial uses of the work are permitted without any further permission from Dove Medical Press Limited, provided the work is properly attributed. For permission for commercial use of this work, please see paragraphs 4.2 and 5 of our Terms (https://www.dovepress.com/terms.php). 
Overall, the results of this study show that Aerobika can, indeed, increase lungs' ventilation, by expanding the volume available for the air passage. Moreover, these changes were accompanied by a shift in the way that the air is distributed throughout the different pulmonary regions, which in turn results in an increase in the patients' standard medication delivery at the lung level.

\section{Introduction}

The presence of mucus along the airway epithelium is a key feature of a healthy and functioning respiratory system: indeed, this mucus is responsible for trapping microorganisms and other particles, which are later removed through the mucociliary escalator and cough. When in excess, however, mucus can assume a pathological nature and lead to a number of complications. Such is the case of chronic obstructive pulmonary disease (COPD): COPD patients typically suffer from excess mucus in their airways, a situation that is caused by an unbalance between an excessive production/secretion and a decreased clearance. ${ }^{1}$ This mucus accumulation leads to obstruction in the small airways and lower respiratory tract infections; moreover, the repeated cycles of inflammation damage the ciliated epithelium, further hampering the mucociliary escalator mechanism. ${ }^{1-3}$ Overall, chronic mucus hypersecretion in COPD patients has been associated with a worsened lung function and a decreased health-related quality of life (HRQoL), as well as to a higher incidence of exacerbations and hospitalisations. ${ }^{1}$ Additionally, this condition is also considered to be a risk factor for respiratory-related and allcause mortality. ${ }^{1,4}$

Airway clearance techniques (ACTs) comprise a number of manual or device-assisted procedures that aim to remove the excess mucus from the airways, promoting a healthy and clear respiratory environment. Positive expiratory pressure (PEP)-based methods are one type of ACTs: patients are asked to breathe through a small, hand-held device, which exerts a gentle resistance during expiration. ${ }^{3}$ This mechanism is thought to prolong the expiratory phase (increasing expiratory capacity), to intensify the intraluminal pressure, and to improve regional alveolar ventilation (by promoting the airflow around and behind the accumulated mucus through the recruitment of collateral airways). ${ }^{3}$ Moreover, the addition of oscillations to PEP may improve the viscoelastic properties of mucus, further contributing towards airways clearance. ${ }^{5,6}$

Aerobika $^{\circledR} \quad$ (Trudell Medical International, London Canada) is an oscillatory PEP (oPEP) device with promising results among the COPD population. In fact, it has recently been reported that COPD patients have a significant improvement in sputum expectoration and clearance after 21 to 28 days of daily Aerobika utilization, coupled with some progress towards a better regional ventilation. ${ }^{7}$ Moreover, sputum-producer patients were shown to have improvements in a number of other parameters, namely forced vital capacity (FVC), 6-minute walk test, Saint George's Respiratory Questionnaire (SGRQ) and Patient Evaluation Questionnaire (PEQ). ${ }^{7}$ Additionally, patients were also shown to benefit from Aerobika in terms of HRQoL: $64 \%$ and $62 \%$ COPD patients with chronic bronchitis had a clinically-meaningful improvement in SGRQ and COPD Assessment Test (CAT) after using this device for three to four or eight weeks, respectively. ${ }^{8}$ Finally, the rate of moderate-to-severe and severe COPD exacerbations (at 30 days) was shown to be significantly lower in patients using Aerobika when compared to matched controls, as were the exacerbations-related mean per patient costs (data from a real-world study). ${ }^{9}$

In spite of the accumulating evidence suggesting the benefits of Aerobika utilization among the COPD population, its physiological basis remains scarcely characterized.

Our aim was to tackle that issue by applying Functional Respiratory Imaging (FRI) to assess the effect of the Aerobika or oPEP device, in addition to standard of care medication, on the lung dynamics and aerosol deposition patterns of COPD patients.

\section{Patients and Methods}

\section{Study Design and Population}

This was a single-arm pilot study designed to assess the impact of Aerobika or oPEP utilization in the lung dynamics and aerosol deposition patterns of sputumproducing COPD patients. Patients with a predicted FEV1 (forced expiratory volume in one second) lower than $80 \%$ (Global Initiative for Chronic Obstructive Pulmonary Disease [GOLD] classification 2-4 ${ }^{10}$ ) and who met the inclusion and exclusion criteria depicted in Supplementary Table 1 were invited to participate. The study protocol was approved by the IRB of the Antwerp University Hospital with approval number 16/40/408. The trial has been submitted to www.clinicaltrials.gov with identification number NCT02936817.

During the screening period, patients were informed on the study procedures and a sham device was used to evaluate subjects' cooperative attitude, as well as to instruct them on the correct use of the oPEP device. 
Patients who agreed to participate in the study and who signed the informed consent form were instructed to use the oPEP device at least twice daily before the administration of their treatment regimen. The device should be used for approximately 10 minutes, after which the patients should rest for about 15 minutes before taking their medication. The treatment period with the oPEP device lasted $15 \pm 3$ days: before and after the experimental period, patients' smoking history/status were reviewed and vital signs were assessed.

\section{Outcome Parameters}

All patients underwent lung function testing and highresolution computed tomography (HRCT) scans at baseline and after the experimental period. Concerning lung function testing, the following parameters were evaluated: FVC, FEV1, PEF (peak expiratory flow) and TLC (total lung capacity). The HRCT scans were used in the FRI analysis, which is a clinically-validated computational work-flow in which functional data are added to respiratory anatomical images. ${ }^{11}$ Shortly, FRI is based on low-dose HRCT scans, from which three-dimensional models of the airways and lungs are extracted. To do so, HRCT scans must be taken during breath-holding at two (spirometry-controlled) distinct lung levels: FRC and TLC. The combination of the models extracted at these two levels allows the assessment of the geometric changes experienced by airways and lung lobes during the breathing cycle. This data is then used as boundary conditions for Computational Fluid Dynamics (CFD) simulations, from which functional information, such as flow behavior and drug deposition, can be calculated. A detailed description of the FRI methodology can be found in De Backer et al. ${ }^{11}$ In this study, the following FRI parameters were evaluated: airway volume (iVaw) and specific airway volume (siVaw), airway resistance (iRaw) and specific airway resistance (siRaw), lobe volumes, air trapping, internal airflow distribution (IAD), low attenuation or emphysema score, blood vessel density or fibrosis score, airwall wall thickness, and mass of deposited particles per defined airway section.

The siVaw and siRaw are normalized measures, calculated by dividing or multiplying (respectively) the correspondent non-specific parameters by the total lung volume.

The mass of deposited particles requires boundary conditions related to the flow domain (HRCT scans), the inhalation profile measured during the study and the aerosol characteristics of the concomitant medications (Mass
Median Aerodynamic Diameter, Geometric Standard Deviation, Fine Particle Fraction and Emitted Dose) derived from scientific literature.

\section{Statistical Analysis}

Given the nature of the data (repeated measurements), each parameter was analyzed using a linear mixed-effect model. ${ }^{12}$ Data related to the airways (iVaw, siVaw, iRaw and siRaw) was logarithmically-transformed prior to analysis. A multi-level model, including fixed effects for visit and lobe, was used to incorporate the repeated measurements from the lobes for each subject. Moreover, lobe was also included as a random effect (within each subject). Heterogeneity across lobes (within each subject) was modelled using an unstructured variance-covariance matrix, with independence assumed between subjects. Degrees of freedom were computed using the Satterthwaite approximation. In the mixed-effect correlation plots, the marginal coefficient of determination $\left(r^{2}\right)$ is shown. In cases where mixed-effects models were not applicable, robust linear models were used. ${ }^{13}$ The robust Wald test was used to evaluate significance. In the robust correlation plots, goodness of fit is assessed using the consistency corrected robust coefficient of determination $\left(r^{2}\right)$. A priori, a p-value of less than 0.05 was considered to be statistically significant.

All statistical analyses are conducted using $\mathrm{R}$ version 3.2.5 or higher (The R Foundation for Statistical Computing, Vienna, Austria).

\section{Results}

Ten patients (seven males and three females, with an average \pm SD age of $67.30 \pm 9.63$ years) agreed to participate in the study (Table 1); all of them were retained until the end of the experimental period. Their lung medication, maintained throughout the trial, is depicted in Supplementary Table 2.

Table 2 and Supplementary Table 3 depict the FRI and clinical parameters $(m e a n \pm S D)$ assessed before and after the addition of oPEP therapy to patients' standard medication. Whereas in most cases there were no significant alterations, a significant increase of $2.88 \%$ was noticed for siVaw after treatment (1.44 (SE: 0.18) vs 1.48 (SE: $0.19) ; 95 \% \mathrm{CI}=[0.03 \%, 5.81 \%] ; \mathrm{p}=0.048)$.

The above-mentioned changes translated into modifications of the internal airflow distribution (IAD): in fact, there was a change in IAD ranging from $-6.74 \%$ to $4.51 \%$, for all lobes. The magnitude of IAD changes postoPEP was heterogeneous per subject and unevenly distributed for the upper and lower lobes, respectively 
Table I Patients' Demographic and Clinical Characteristics

\begin{tabular}{|c|c|c|c|c|c|c|c|c|}
\hline Subject $n^{\circ}$ & Sex & Age (y) & Height (cm) & Weight (kg) & FVC (L) & FEVI (L) & FEVI (\% Pred) & FEVI/FVC \\
\hline I & $\mathrm{F}$ & 57 & 160 & 58 & 2.74 & 0.89 & 38.78 & 0.32 \\
\hline 2 & M & 78 & 172 & 71 & 4.45 & 1.66 & 62.78 & 0.37 \\
\hline 3 & M & 73 & 170 & 76 & 3.86 & 1.53 & 56.60 & 0.40 \\
\hline 4 & $M$ & 71 & 168 & 74.8 & 4.53 & 2.25 & $84.11^{\dagger}$ & 0.50 \\
\hline 5 & $M$ & 51 & 179 & 80 & 5.56 & 2.71 & 72.69 & 0.49 \\
\hline 6 & $M$ & 74 & 165 & 89 & 1.73 & 0.75 & 30.50 & 0.43 \\
\hline 7 & $\mathrm{~F}$ & 63 & 161 & 97 & 2.88 & 1.35 & 61.80 & 0.47 \\
\hline 8 & M & 81 & 165 & 56.9 & 2.05 & 0.98 & 43.44 & 0.48 \\
\hline 9 & M & 61 & 175 & 82.9 & 4.42 & 2.27 & 69.50 & 0.51 \\
\hline 10 & $\mathrm{~F}$ & 64 & 158 & 48 & 2.50 & 0.64 & 31.36 & 0.26 \\
\hline Average & - & 67.3 & 167.30 & 73.36 & 3.47 & 1.50 & 55.16 & 0.42 \\
\hline SD & - & 9.63 & 6.80 & 15.29 & 1.26 & 0.72 & 18.37 & 0.08 \\
\hline
\end{tabular}

Abbreviations: FVC, forced vital capacity; FEVI, forced expiratory volume in one second. †patient was considered eligible by principal investigator based on FEVI within error of measurement and adapted clinical profile (medical history GOLD IIB).

Table 2 Clinical and FRI Parameters (Mean \pm SD) Before and After (15 \pm 3 Days) Aerobika ${ }^{\circledR}$ Treatment

\begin{tabular}{|l|l|l|l|}
\hline Parameter & Before & After & $\begin{array}{l}\text { p (Linear } \\
\text { Mix Effect } \\
\text { Model) }\end{array}$ \\
\hline siVaw (mL/L) at TLC & $1.62 \pm 0.85$ & $1.65 \pm 0.85$ & 0.048 \\
siVaw (mL/L) at FRC & $0.93 \pm 0.53$ & $0.93 \pm 0.51$ & 0.983 \\
siRaw (kPa s) at TLC & $0.18 \pm 0.15$ & $0.16 \pm 0.11$ & 0.142 \\
siRaw (kPa s) at FRC & $0.15 \pm 0.16$ & $0.17 \pm 0.20$ & 0.084 \\
iVlobe (L) at TLC & $1.23 \pm 0.51$ & $1.24 \pm 0.52$ & 0.106 \\
iVlobe (L) at FRC & $0.81 \pm 0.31$ & $0.81 \pm 0.34$ & 0.956 \\
AT (\%) at FRC & $50.15 \pm 24.57$ & $50.00 \pm 25.55$ & 0.873 \\
IVbv (\%) at TLC & $2.11 \pm 0.84$ & $2.09 \pm 0.78$ & 0.582 \\
LAS (\%) at TLC & $14.38 \pm 14.62$ & $13.69 \pm 14.40$ & 0.197 \\
\hline
\end{tabular}

Abbreviations: SD, standard deviation; TLC, total lung capacity; FRC, functional residual capacity; siVaw, specific airways volume; siRaw, specific airways resistance; iVlobe, lobal volume; AT, air trapping; IVbv, blood vessel volume; LAS, low attenuation score; IAD, internal airflow distribution.

(Figure 1). Moreover, Table 3 shows correlations between post-oPEP changes in lung function parameters and change in IAD. Post-oPEP changes in FEV1 $\left(r^{2}=0.50\right.$; $\mathrm{p}=0.032)$ and PEF $\left(r^{2}=0.29 ; \mathrm{p}=0.007\right)$ were positively correlated with change in IAD at the lower lobes meaning that an increase in ventilation towards the lower lobes resulted in an increase in those lung function parameters. However, the post-oPEP changes for FEV1 $\left(r^{2}=0.50\right.$; $\mathrm{p}=0.032)$ and PEF $\left(r^{2}=0.29 ; \mathrm{p}=0.007\right)$ were inversely correlated with change in IAD at the upper lobes. Interestingly, the change in IAD was significantly correlated with changes in lobar drug deposition $\left(r^{2}=0.30\right.$, $\mathrm{p}<0.001$ ) - Figure 2 .

Given the heterogeneity of these results, it is worth to look at IAD at an individual level. Figure 3 illustrates the internal airflow shift post-oPEP for two patients, subject 5 and subject 9. Subject 9 presents an increase of $6.88 \%$ in the IAD towards the lower lobes. As a result, this patient experienced a $14.72 \%$ increase in his average aerosol deposition in the right lower lobe, accompanied by a $20.45 \%$ increase in the left lower one. From a clinical perspective, these changes resulted in a FEV1 improvement of $0.17 \mathrm{~L}$. Subject 5, on the other hand, presented a similar tendency - ie, a shift in the IAD towards the lower lobes - although with a smaller value $(2.78 \%)$. Overall, this patient experienced a slight improvement of FEV1 (0.07L), but no general improvement in lobar drug deposition, although one could see a relatively larger deposition in the lower lobes when compared to the upper ones.

\section{Discussion}

In this study, ten sputum producing COPD patients (with moderate to severe airflow limitation severity) added two daily sessions with the oPEP device to their standard medication. Our main aim was to understand the impact of oPEP on lung dynamics and medication deposition. To do so, standard lung function assessments and FRI parameters were evaluated before and after the experimental period. Overall, the results indicate that even after a short period (approximately two weeks), oPEP utilization increases siVaw. These changes affect the IAD, which in turn is significantly correlated with particles deposition at lung lobes: in fact, an improvement of ventilation distribution is accompanied by an increase in the lobar drug deposition of the concomitant medication. 
Internal Airflow Distribution (IAD) before and after oPEP

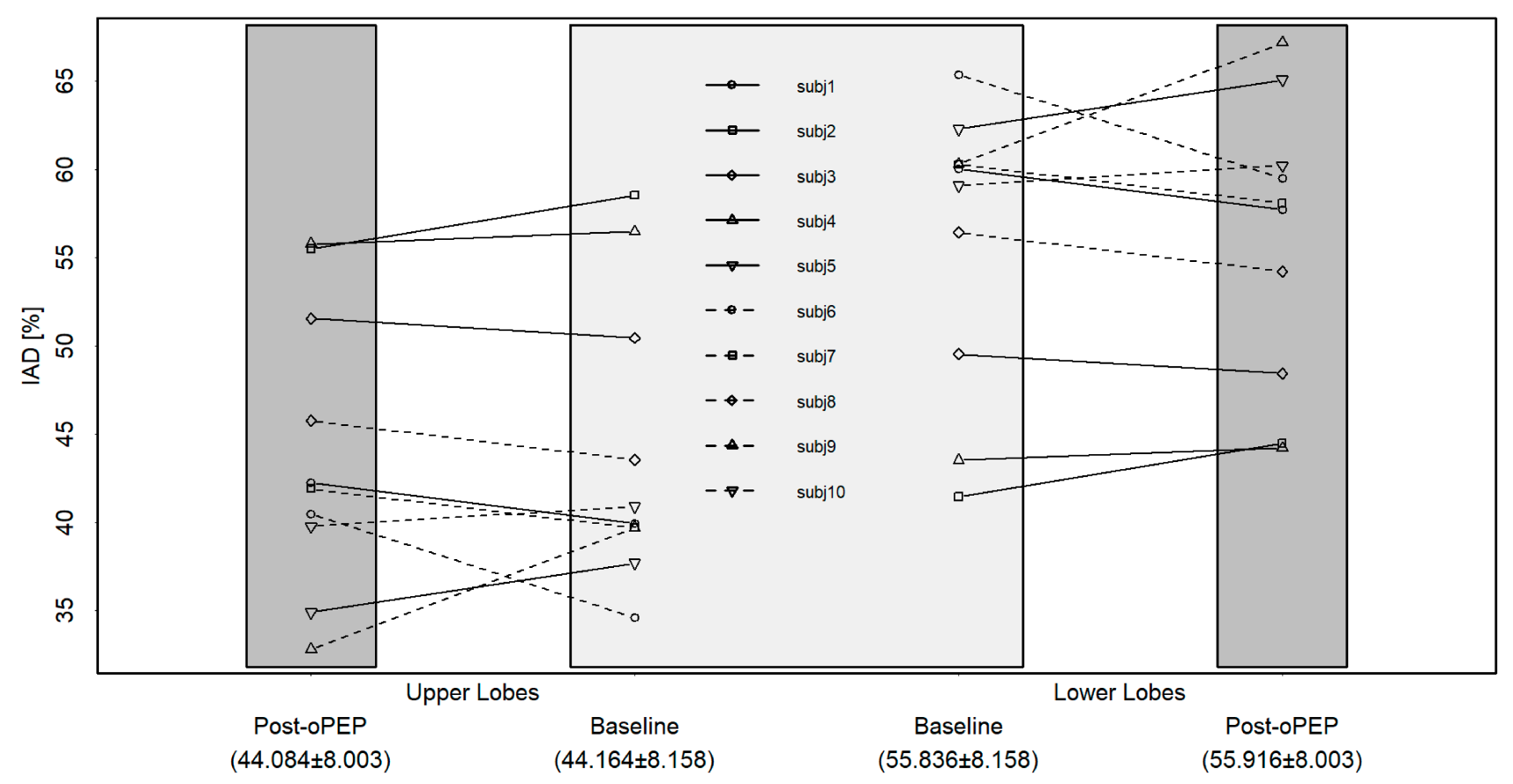

Figure I Individual changes in IAD between baseline and post-oPEP for upper and lower lobes.

Note: The upper lobe value per subject is the sum of the IAD value of the right upper lobe, right middle lobe and left upper lobe. The lower lobe value per subject is the sum of the IAD value of the right lower lobe and left lower lobe. The mean \pm SD for upper and lower lobes respectively are indicated in the $X$-axis.

Abbreviation: IAD, internal airflow distribution.

One may argue that the changes in siVaw are rather small $(2.88 \%)$ and although this is true, it is worth noticing that a similar small change $(1.50 \%)$ was obtained in a previous study assessing an established pharmaceutical compound (extrafine beclomethasone/formoterol [BDP/F]) in 27 COPD patients in a chronic setting. ${ }^{14}$ Inhaled corticosteroids (ICS) are thought to act through a remodeling of the airways after at least four to six weeks of use. In the study by De Backer et al, a significant reduction of the hyperinflation at the lobar level was noticed six months after the study onset. ${ }^{14}$ These changes are likely related with the ICS effect (rather than with the long-acting $\beta_{2}$ agonist one), suggesting that the improvement in siVaw, as

Table 3 Correlations (Robust Linear Model) Between Clinical Data and IAD Change After Aerobika ${ }^{\circledR}$ Treatment

\begin{tabular}{|l|l|l|l|}
\hline & & $r^{2}$ & $P$ \\
\hline$\Delta \mathrm{IAD}(\%)$ in UL & $\Delta \mathrm{FEVI}(\mathrm{L})$ & -0.50 & 0.032 \\
& $\Delta \mathrm{PEF}(\mathrm{L} / \mathrm{s})$ & -0.29 & 0.007 \\
\hline \multirow{2}{*}{$\Delta \mathrm{IAD}(\%)$ in LL } & $\Delta \mathrm{FEVI}(\mathrm{L})$ & 0.50 & 0.032 \\
& $\Delta \mathrm{PEF}(\mathrm{L} / \mathrm{s})$ & 0.29 & 0.007 \\
\hline
\end{tabular}

Abbreviations: IAD, internal airflow distribution; FRC, functional residual capacity; TLC, total lung capacity; UL, upper lobes; LL, lower lobes; FEVI, forced expiratory volume in one second; PEF, peak expiratory flow. small as it may appear, did in fact translate into a clinical benefit. As so, one may extrapolate that the similar siVaw response in our study does mean that the oPEP device has a clinically meaningful impact in airways' geometry. Further studies, with larger samples, should be able to clarify this issue by enhancing the magnitude of the observed differences.

Moreover, changes in siVaw have been previously correlated to symptomatology. In fact, in the study by Vos et al, 24 asthma patients treated with extrafine BDP/F for six months experienced a number of improvements in prebronchodilation imaging parameters, including the small airways volume. ${ }^{15}$ Interestingly, this increase in airways volume was directly and significantly correlated with changes in asthma symptom score (ACT), further supporting that airways geometry changes are of clinical significance.

Regarding the relationship between IAD distribution and FEV1 improvement on an individual level, the results in our pilot study support what has been previously observed by Svenningsen et al. ${ }^{7}$ These authors analysed the impact of the same oPEP device in COPD patients (sputum producers and non-producers), and although they were unable to demonstrate statistically significant changes concerning ventilation redistribution, their results show that patients responding on oPEP 


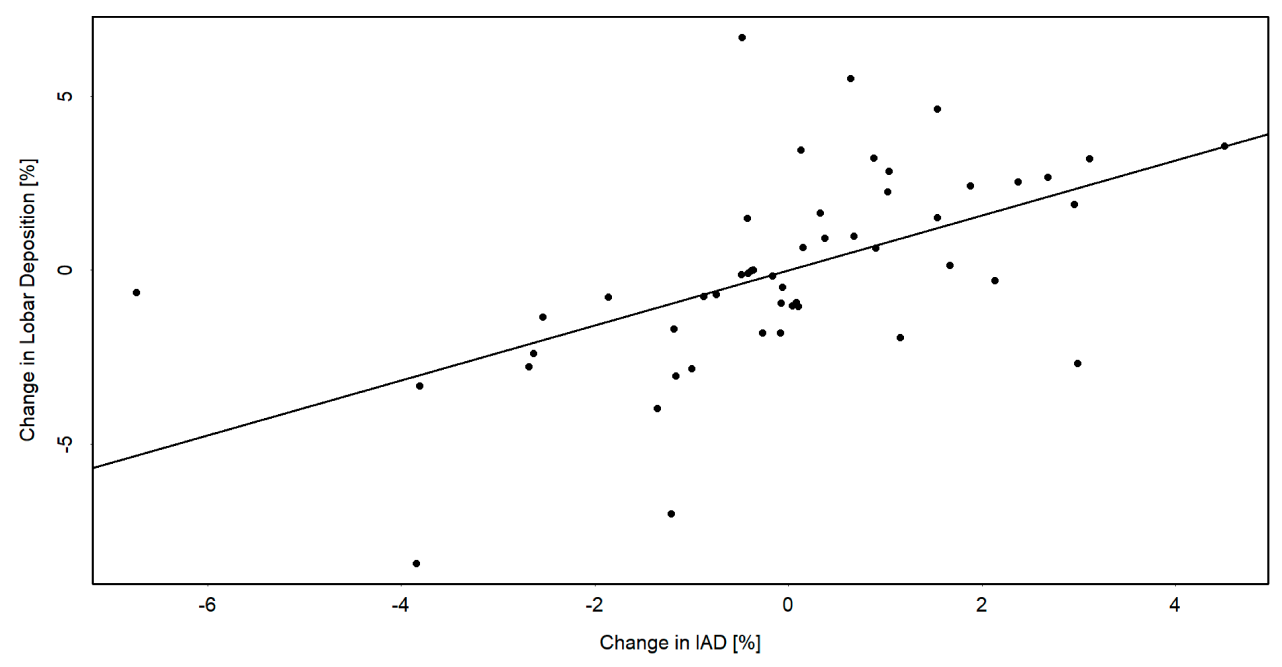

Figure 2 Correlation between lobar drug deposition changes and IAD changes after oPEP treatment. Note: marginal $r^{2}$ (linear mixed-effect model) $=0.30, p<0.001$.

Abbreviation: IAD, internal airflow distribution.

Patient 9
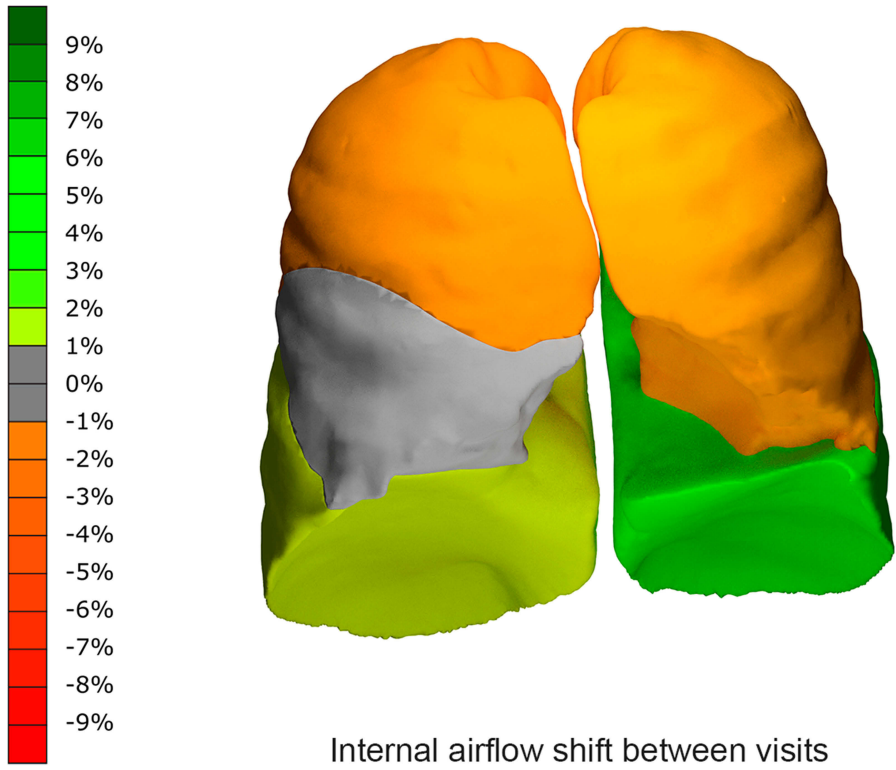

Internal airflow shift between visits FEV1 improvement: 0.17L
Patient 5

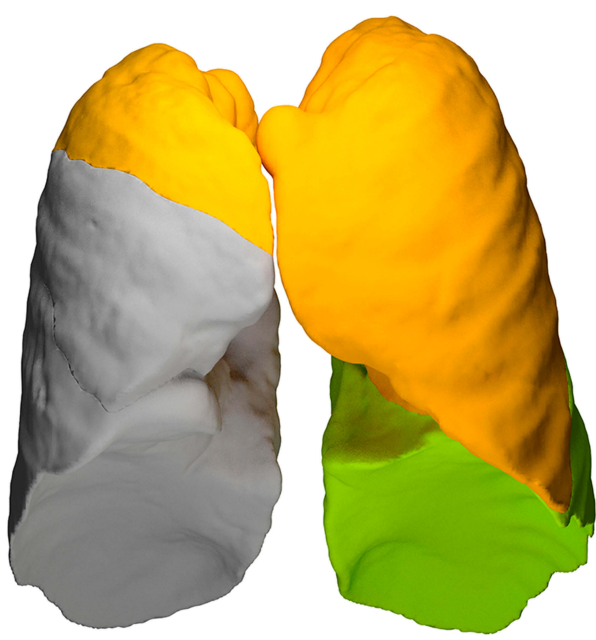

Internal airflow shift between visits FEV1 improvement: 0.07L

Figure 3 Changes of IAD throughout the experimental period for Subject 9 (left) and Subject 5 (right). Abbreviation: IAD, internal airflow distribution.

in terms of FEV1 do show a greater redistribution of ventilation towards the lower lobes. ${ }^{7}$ Moreover, a similar mode of action between changes in IAD and more effective deposition was also observed by De Backer et al in patients with COPD who are prone to dynamic hyperinflation when administered a PDE4 inhibitor on top of triple therapy (LABA/LAMA/ ICS). According to the authors, the rationale behind the clinical improvement in FEV1 in their clinical trial is probably the result of a more effective deposition of the triple therapy caused by changes in IAD which are related to an improvement in the smaller airways trough the anti-inflammatory characteristics of the orally administered PDE4. ${ }^{16,17}$

Despite the promising insights mentioned above, the current study had some limitations. Firstly, although we observe positive results for oPEP regarding drug deposition, it is a small sample size and larger studies with a control group are needed 
to confirm our results. Secondly, the majority of the patients enrolled were male $(70 \%)$. It is documented in literature that women have lower luminal area, internal diameter and airway thickness of segmental and subsegmental bronchi in comparison with men. ${ }^{18}$ This gender related difference in airway morphology could impact local drug deposition patterns, ${ }^{19}$ so these results should be interpreted with some caution for female subjects. Thirdly, our results were rather heterogeneous. This might be related with the fact that the ventilation patterns of sputum-producing patients are heterogeneously distributed by nature, as noted before. ${ }^{7,20}$ In addition to the inherent heterogeneity by the disease, the study design might have had some impact at this level as well: in fact, treatment period was relatively short ( 15 days $v s$ three to four weeks in the reference trial). ${ }^{7}$ Furthermore, patients were asked to use the device at their final visit, and Hortal and Hjelte have shown that the time elapsed from chest physiotherapy (another form of ACT) and lung function testing in cystic fibrosis patients impacts the spirometry results. ${ }^{21}$ More specifically, FEV1 changes were significant when the assessment was made between 30 minutes and two hours after physiotherapy, but lacked significance when assessed before or after that interval. The absence of significant results when the tests were made immediately after the ACT are likely due to the subsequent mucus shift from the peripheral airways to the central airways, which has a negative influence on FEV1. As such, the fact that the patients in this study were assessed shortly after using the Aerobika device cannot be disregarded as a source of heterogeneity. Indeed, Ides et al analyzed the effect of intrapulmonary percussive ventilation (IPV) in COPD patients, having reported a shift of mucus coupled with a lack of significant changes in spirometry tests (which took place within $60 \mathrm{~min}$ of the IPV session). ${ }^{22}$ As such, the inclusion of an adequate time interval between the device utilization and parameters' assessment should be taken into account in future studies.

\section{Conclusions}

Overall, our results provide evidence that a short treatment period with oPEP, in particularly the Aerobika device, on top of concomitant medication is able to improve airway geometry and redistribute the airflow, consequently influencing drugs' deposition patterns in COPD patients.

\section{Data Sharing Statement}

The data that supports the findings of this study will not be shared openly with other third parties due to contractual statements related to intellectual property, confidentiality, and proprietary rights.

\section{Ethics Approval and Informed Consent}

All patients enrolled in the study signed an informed consent form. Enrollment started from time of first participant consent at 12 January 2017 until the follow-up visit of the last participant at 28 August 2017. This study was conducted in compliance with the approved protocol, Good Clinical Practice (GCP), Declaration of Helsinki and all applicable regulatory requirements, registered at ClinicalTrials.gov with the reference NCT02936817 and approved by the Institutional Research Board of the Antwerp University Hospital with approval number 16/40/408.

\section{Acknowledgments}

The authors would like to acknowledge Catarina L Santos (W4Research) for medical writing assistance.

\section{Funding}

The study was funded by Trudell Medical International.

\section{Disclosure}

Glenn Leemans is affiliated with the University of Antwerp and responsible for the statistical analysis, clinical interpretation and discussion of the results. He was employed by FLUIDDA when the study was conducted. Dennis Belmans and Cedric Van Holsbeke are affiliated with FLUIDDA and also responsible for statistical analysis, clinical interpretation and discussion of the results. Wilfried De Backer, Kris Ides and Dirk Vissers are affiliated with the University of Antwerp and contributed with clinical experience to the analysis and discussion of results. Wilfried De Backer also received compensation for study costs from University Hospital of Antwerp, during the conduct of the study. Vladimir Kushnarev and Jason Suggest are employees of Trudell Medical International, sponsor of the study. The authors report no other conflicts of interest in this work.

\section{References}

1. Ramos FL, Krahnke JS, Kim V. Clinical issues of mucus accumulation in COPD. Int J COPD. 2014;9:139-150.

2. Volsko T. Airway clearance therapy: finding the evidence. Respir Care. 2013;58(10):1669-1678. doi:10.4187/respcare.02590

3. Osadnik CR, McDonald CF, Holland AE. Airway clearance techniques for chronic obstructive pulmonary disease. Expert Rev Respir Med. 2013;7(6):673-685. doi:10.1586/17476348.2013.847368

4. Prescott E, Lange P, Vestbo J. Chronic mucus hypersecretion in COPD and death from pulmonary infection. Eur Respir J. 1995;8 (8):1333-1338. doi:10.1183/09031936.95.08081333 
5. Osadnik CR, McDonald CF, Holland AE, Ramos FL, Krahnke JS, Kim V. Clinical issues of mucus accumulation in COPD. Int J Chron Obstruct Pulmon Dis. 2014;9:139-150. doi:10.2147/COPD.S38938

6. Ides K, Vissers D, Vissers D, De Backer L, Leemans G, De Backer W. Airway clearance in COPD: need for a breath of fresh air? A systematic review. COPD. 2011;8(3):196-205. doi:10.3109/ 15412555.2011.560582

7. Svenningsen S, Paulin GA, Sheikh K, et al. Oscillatory positive expiratory pressure in chronic obstructive pulmonary disease. COPD. 2016;13(1):66-74. doi:10.3109/15412555.2015.1043523

8. Suggett J. Quality of Life (QOL) responder rate analysis following use of an Oscillating Positive Expiratory Pressure (OPEP) device for Chronic Obstructive Pulmonary Disease (COPD): SGRQV CAT assessments - abstract presentations, COPD10, Birmingham, United Kingdom. Chronic Obs Pulm Dis. 2017;4(3):225-246.

9. Burudpakdee C, Seetasith A, Dunne P, et al. A real-world study of 30-day exacerbation outcomes in chronic obstructive pulmonary disease (COPD) patients managed with aerobika OPEP. Pulm Ther. 2017;3(1):163-171. doi:10.1007/s41030-017-0027-5

10. Global Initiative for Chronic Obstructive Lung Disease (GOLD). Global Strategy for the Diagnosis, Management, and Prevention of Chronic Obstructive Pulmonary Disease - 2019 Report. Glob Initiat Chronic Obstr Lung Dis Inc; 2019.

11. De Backer JW, Vos WG, Vinchurkar SC, et al. Validation of computational fluid dynamics in CT-based airway models with SPECT/CT. Radiology. 2010;257(3):854-862. doi:10.1148/radiol.10100322

12. Bates D, Mächler M, Bolker BM, Walker SC. Fitting linear mixed-effects models using lme4. J Stat Softw. 2015;67(1). doi:10.18637/jss.v067.i01

13. Koller M, Stahel WA. Sharpening Wald-type inference in robust regression for small samples. Comput Stat Data Anal. 2011;55 (8):2504-2515. doi:10.1016/j.csda.2011.02.014

14. De Backer J, Vos W, Vinchurkar S, et al. The effects of extrafine beclometasone/formoterol (BDP/F) on lung function, dyspnea, hyperinflation, and airway geometry in COPD patients: novel insight using functional respiratory imaging. J Aerosol Med Pulm Drug Deliv. 2014;27:1-12. doi:10.1089/jamp.2013.1049
15. Vos W, Backer De J, Poli G, et al. Novel functional imaging of changes in small airways of patients treated with extrafine beclomethasone/formoterol. Respiration. 2013;86(5):393-401. doi:10.1159/000347120

16. De Backer W, Vos W, Van Holsbeke C, et al. The effect of roflumilast in addition to LABA/LAMA/ICS treatment in COPD patients. Eur Respir J. 2014;44(2):527-529. doi:10.1183/09031936.00011714

17. Vos W, Hajian B, De Backer J, et al. Functional respiratory imaging to assess the interaction between systemic roflumilast and inhaled ICS/ LABA/LAMA. Int J Chron Obstruct Pulmon Dis. 2016;11:263-271. doi:10.2147/COPD.S93830

18. Kim Y, Schroeder J, Lynch D, et al. Gender differences of airway dimensions in anatomically matched sites on CT in smokers. COPD J Chronic Obstr Pulm Dis. 2011;8(4):285-292. doi:10.3109/ 15412555.2011.586658

19. Kim CS, Hu SC. Regional deposition of inhaled particles in human lungs; comparison between men and women. J Appl Physiol. 1998;84 (6):1834-1844. doi:10.1152/jappl.1998.84.6.1834

20. Svenningsen S, Guo F, McCormack DG, Parraga G. Noncystic fibrosis bronchiectasis: regional abnormalities and response to airway clearance therapy using pulmonary functional magnetic resonance imaging. Acad Radiol. 2017;24(1):4-12. doi:10.1016/j.acra.2016.08.021

21. Rodriguez Hortal MC, Hjelte L. Time point to perform lung function tests evaluating the effects of an airway clearance therapy session in cystic fibrosis. Respir Care. 2014;59(10):1537-1541. doi:10.4187/ respcare. 02823

22. Ides K, Vos W, De Backer L, et al. Acute effects of intrapulmonary percussive ventilation in COPD patients assessed by using conventional outcome parameters and a novel computational fluid dynamics technique. Int J Chron Obstruct Pulmon Dis. 2012;7:667-671. doi:10.2147/COPD.S29847

\section{Publish your work in this journal}

The International Journal of COPD is an international, peer-reviewed journal of therapeutics and pharmacology focusing on concise rapid reporting of clinical studies and reviews in COPD. Special focus is given to the pathophysiological processes underlying the disease, intervention programs, patient focused education, and self management protocols. This journal is indexed on PubMed Central, MedLine and CAS. The manuscript management system is completely online and includes a very quick and fair peer-review system, which is all easy to use. Visit http://www.dovepress.com/testimonials.php to read real quotes from published authors.

Submit your manuscript here: https://www.dovepress.com/international-journal-of-chronic-obstructive-pulmonary-disease-journal 